\title{
Efficacy of an Intense Rifle Fencing Training
}

\author{
José Antonio Aguirre-Puig ${ }^{1}$, Vicente Javier Clemente-Suarez ${ }^{2}$, Pedro Montañez-González and José \\ Juan Robles-Pérez ${ }^{3, *}$
}

${ }^{1}$ I Airborne Flag, Airborne Brigade, Spanish Army, Paracuellos del Jarama, Madrid, Spain

${ }^{2}$ Department of Physical Activity and Sport Science, Sport Science Faculty, University of Castilla la Mancha, Toledo, Spain

${ }^{3}$ Department of Close Combat and Self Defense, Military Sports Area, Central School of Physical Education of the Army, Toledo, Spain

\begin{abstract}
The present study aimed to analyze the effectiveness of an intensive rifle fencing training based on a couple of the most effective fencing techniques compared to a traditional fencing training. 20 male professional soldiers of Spanish Army (28.6 \pm 2.4 years) were randomly divided in an experimental group (n: 10) and control group (n: 10). After $1 \mathrm{~h}$ rifle training sessions during 6 days, soldiers conducted simulated close quarter combats with rifles. Results showed that the experimental group obtained higher number of victories (17.0 vs. 7.0), number of techniques used (13.0 vs. 6.0), and had variations in body location of impact (head, trunk, legs and arms vs. head, trunk and arms) than control group. The experimental rifle fencing training focused on selected fencing techniques was more effective than the traditional rifle fencing training focused on a higher technical repertory.
\end{abstract}

Keywords: Close quarter combat, fencing, melee, rifle techniques, soldier.

\section{INTRODUCTION}

In current theaters of operations, asymmetrical conflicts predominate (non defined battlefield), characterized by combat in urban areas in constant evolution and with presence of civilians. These asymmetrical conflicts are in constant change and the soldier must be prepared for unexpected attacks, close quarter and melee combats. Under stress our brain reacts with one of the basic human instincts, aggressiveness allowing individual survival [1-3]. For this reason, it is important to analyze the instinctive reactions and modulate to improve combat performance $[4,5]$.

The relevance of close quarter and melee combats could be underestimated because of the advantages provided by firearms, but conflicts in 19th century showed us the opposite. During World War I, there were many melees and the cleaning-trenches for example, were famous for these melee actions so the use of close quarter techniques. In World War II, melee combats were famous in battles such as Stalingrad or Iwo Jima. Also in the Falklands War (1982), the British commands succeeded in three days applying close quarter and melee technique what conventional weapons had not achieved in three months.

*Address correspondence to this author at the Department of Melee Combat and Self Defense, Military Sports Area. Central School of Physical Education of the Army, 45009, Toledo, Spain; Tel: (+34) 6547775 10; Fax: (+34) 916907826; E-mail: jose_robles_perez@hotmail.com
Actually peacekeeping operations constitute one of the principal actions conducted by principal armies in the world. Soldiers have to respect the rules of engagement and also the tasks developed are conducted without shot of the rifle, therefore the knowledge of techniques of rifle fencing and close quarter combat is important to achieve the assigned tasks [6]. The influence of combat stress could modify the actuation of soldiers in combat, making their actions more irrationals and innate [3], for this reason the instructions of more natural and innate fencing techniques could be an efficient strategy to improve the performance on fencing combat of soldiers as previous authors supported [4]. Due to the importance of rifle fencing techniques, especially in actual conflicting areas in which the distance of combat is reduced and close quarter combat techniques being fundamental to the survival of soldiers [6], and the necessity to improve the traditional rifle fencing training programs making them more efficient and effective, we conducted the present research with the aim to analyze the effectiveness of an experimental intensive rifle fencing training in professional soldiers. It was hypothesized that the experimental rifle fencing training would obtain higher performance than traditional fencing training.

\section{METHODS}

The sample consisted of 20 male soldiers of Spanish Army (28.6 \pm 2.4 years) who have served in the Army, Air Force and Navy. All subjects had minimum 4 years of professional experience in their units; some of them had experience in international missions in current conflicts: 

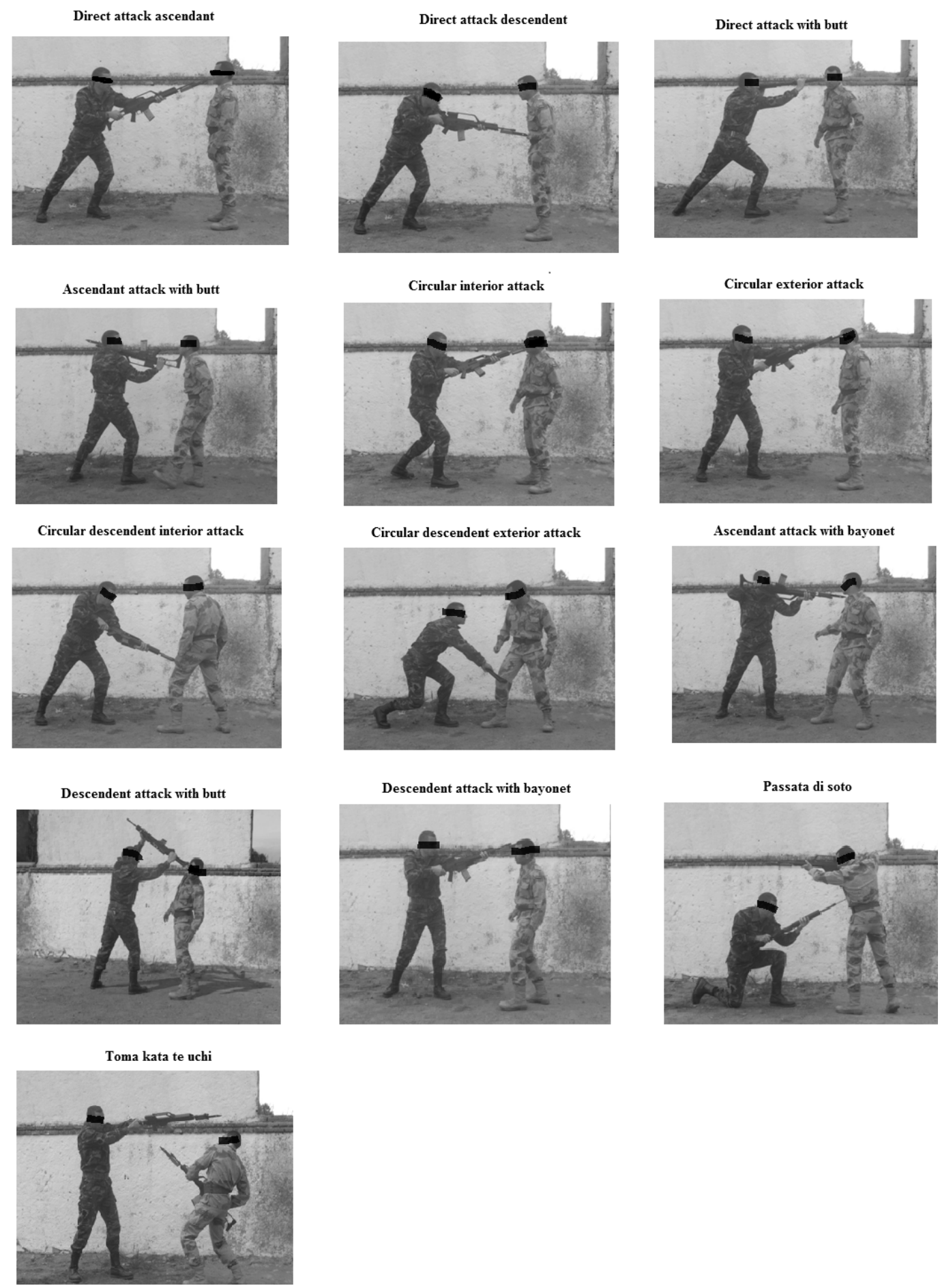

Fig. (1). Techniques trained.

Lebanon, Afghanistan, Bosnia, Kosovo and Iraq. Prior to participation, the experimental procedures were explained to all the participants, who gave their voluntary written informed consent in accordance with the Declaration of Helsinki.

Performance in fencing rifle combat was analyzed in two groups after performing an intense experimental fencing rifle training and a traditional fencing rifle training. Soldiers were randomly assigned to an experimental $(n=10)$ or control group $(n=10)$. Experimental group performed $1 \mathrm{~h}$ rifle fencing training sessions 3 days per week during 2 weeks.
This group was trained only a selected number of techniques, considered the most effective by the rifle fencing instructors. These techniques were as follows: direct attack ascendant, direct attack descendent, direct attack with butt, ascendant attack with butt, circular interior attack, circular exterior attack, circular descendent interior attack, circular descendent exterior attack, ascendant attack with bayonet, descendent attack with butt, descendent attack with bayonet, "passata di soto" and "toma kata te uchi". These techniques are presented in Fig. (1). Control group performed the normal rifle fencing training with a repertory of 200 
Table 1. Combat Action Where the Techniques were Performed

\begin{tabular}{|c|c|c|}
\hline Combat Action & Experimental Group (\%) & Control Group (\%) \\
\hline \hline Attack & 72 & 88 \\
\hline Counter & 0 & 0 \\
\hline Anticipation & 14 & 0 \\
\hline $\begin{array}{c}\text { Concatenation } \\
\text { (linked techniques) }\end{array}$ & 14 & 0 \\
\hline
\end{tabular}

Table 2. Body Location of Impacts.

\begin{tabular}{|c|c|c|}
\hline Body Location & Experimental Group (\%) & Control Group (\%) \\
\hline \hline Head & 26 & 6 \\
\hline Trunk & 53 & 0 \\
\hline Legs & 3 & 25 \\
\hline Arms & 18 & 69 \\
\hline
\end{tabular}

techniques [6] during the same period and the same time. Training sessions were performed with an HK-G36 rifle and consisted in the explication of the techniques, practicing the basic movement and applications of the technique in combat.

To analyze the effectiveness of the two training programs 24 randomly bouts were performed between the soldiers of the experimental and the control groups. Before combats, subjects performed a standardized individual warm up consisting in aerobic running and stretching exercises lasting for $15 \mathrm{~min}$. For safety reason soldiers used a replica of the HK-G36 rifle. Soldiers were equipped with the standard uniform of the army without girdle and boots, with a padded helmet while HK-G36 replica was used for safety reasons. Combats were performed in a $4 \mathrm{~cm}$ thick tatami. The objective of the combat was to neutralize the opponent using rifle melee techniques. The combat was a victory when one fighter obtained 1 point according to the following range of scores.

- Percussive blow to head or trunk: 1 point.

- Percussive blow to limbs: 0.5 point

- No percussive blow to head or trunk: 0.5 point.

- No percussive blow to limbs: 0 points.

- Forcefully projection and control of the situation: 1 point.

A jury composed by 3 army instructors was arbitrating combats, and to score any punctuation at least 2 of them had to confirm the technique and the punctuation. All the combats were filmed by a video camera (Panasonic SD40) to analyze the body location of the impact and the technique used.

Number of blow points, number of victories, percentages of use of each technique (\%) and body location of impact (body, arms, legs or head), combat action of the technique (attack, defense, anticipation or concatenation) were measured during the combats.
All data analyses were performed using the SPSS 15.0 statistical program. The Shapiro-Wilk normality test was used to test homogeneity of each variable. A dependent-T test was performed to analyze differences between groups. The level of significance for all the comparisons was set at $\mathrm{p}<0.05$

\section{RESULTS}

Experimental group reached a significantly $(\mathrm{p}<0.05)$ higher number of point blows than control groups (37.0 vs. 17.0 respectively). Also the experimental group had a significantly higher number of victories in combats than control groups (17.0 vs. 7.0 respectively).

Both groups realized the majority of the techniques in attack actions (Table 1).

The majority of the blows were in the trunk in both groups (Table 2), and the most used technique in both groups was the direct attack, but the distribution of percentage of use was different in the experimental group compared to the control group (Table $\mathbf{3}$ ).

\section{DISCUSSION}

The aim of the present study was to analyze the effectiveness of an experimental intensive rifle fencing training in professional soldiers. The experimental group showed a significantly higher number of wins and number of hits. These results support the theories of previous authors $[4,7-9]$ that postulated the necessity to train a small groups of combat techniques that soldiers could use in high stress situations. These results are also in consonant with the thesis of Hayes and Ress [10] since the techniques trained in the experimental training program were considered more inmates than the rest of techniques trained in the traditional training program, fact that could help to learn them faster. Also, a possible explanation for the quick results achieved could be the biomechanics characteristics of the rifle fencing 
Table 3. Rifle Techniques Used

\begin{tabular}{|c|c|c|}
\hline Techniques & Experimental Group (\%) & Control Group (\%) \\
\hline Descendent attack on head & 5 & 0 \\
\hline Descendent exterior attack $\left(45^{\circ}\right)$ & 14 & 6 \\
\hline Circular attack on knee & 3 & 0 \\
\hline Circular butt & 0 & 6 \\
\hline Descendent attack on forearm in anticipation & 5 & 0 \\
\hline Descendent attack on head in anticipation & 3 & 0 \\
\hline Direct attack with butt & 0 & 6 \\
\hline Descendent attack on forearm with butt & 0 & 6 \\
\hline Condecatenation direct attack-descendent exterior attack & 3 & 0 \\
\hline Condecatenation direct attack-direct attack & 5 & 0 \\
\hline Condecatenation descendent attack on forearm-direct attack & 5 & 0 \\
\hline
\end{tabular}

techniques and the teaching methodology used, accordingly with the methods proposed by Thabot [11] and Thiess et al. [12] to teach technical and tactical combat schemes, based on a small group of techniques in opposition to the high volume of exercises of the traditional training that may disrupt the motor learning concentration and consequently giving less time to the trainees to adapt the training characteristics.

The analysis of data showed that attack is the most important action to win the combat, since $72 \%$ and $88 \%$ of points were reached in this action by experimental and control groups respectively. Another aspect to consider is that control group focused its combat actions on attacks (88\%) leading the majority of them to the trunk. In contrast experimental group presented higher variability in the impact body areas, showing higher versatility and a better application of the techniques learned, that is a basic requisite to obtain a victory in a combat [13]. Regarding the techniques used, results indicate that soldiers acquired a higher technical diversity with the experimental training that helps to cope with higher capacities successful combat situations [13-15], since experimental group used 13 different fencing techniques and control group just used 6 fencing techniques, focusing basically on the direct attack ( $71 \%$ of techniques used).

The experimental rifle fencing training allowed assimilating the principal and most useful fencing techniques in a short time lapse. Previous authors $[15,16]$ showed the primacy of instinctive on technical action in real combat situations, showing reduced combat techniques repertoires. The present research showed that soldiers could realize a higher number of techniques and obtain higher number of victories, that shows the importance of knowledge of an amply repertory of combat techniques. The data suggest the necessity to broaden the technical variety of soldiers focusing on the most efficient technique to improve survival and increase the variety of body location impacts to gain the initiative. For this purpose, soldiers must be trained with a technical and tactical scheme based on simple, basic and instinctive small group of techniques and trainings in different tactical situations as attack, counter, anticipation and combination. The application of the experimental rifle fencing training is equally valid for both symmetric and asymmetric combat situations because of the techniques taught are efficient in each combat situation [17, 18], and are in consistent with the international use of force law and the studies about the use of force in actual operation areas $[6,15]$. The introduction of this type of instruction training in military units is important as part of the soldier's training programs since these abilities could be decisive in the actual international missions in which many complex situations arise that require increasingly comprehensive preparation.

\section{CONCLUSION}

Fencing training techniques focused on the most important fighting drills obtained higher results as compared to the traditional rifle fencing training focused on a large number of fighting drills.

\section{CONFLICT OF INTEREST}

The authors confirm that this article content has no conflict of interest. 


\section{ACKNOWLEDGEMENTS}

Declared none.

\section{REFERENCES}

[1] Benyamini Y, Solomon Z. Combat stress reactions, posttraumatic stress disorder, cumulative life stress, and physical health among Israeli veterans twenty years after exposure to combat. Soc Sci Med 2005; 61: 1267-77.

[2] Helmus T, Glenn R.. Steeling the Mind, Combat Stress reactions and Their Implications for Urban Warfare. Santa Mónica, California: Rand Corporation 2005.

[3] Attias J, Bleich A, Furman V, Zinger Y. Event-related potentials in post-traumatic stress disorder of combt origin. Biol Psychiatry 1996; 40: 373-81.

[4] Fujita S, Plee H. El arte sublime y último de los puntos vitales. Noisy-sur-École, Francia: Budo ed 2000.

[5] McLean P. The triune brain evolution. New York, NY: Plenum press 1990.

[6] Robles J, Alba C, Lumbreras V, Duce J. Manual de instrucción de combate cuerpo a cuerpo e intervención no letal. Toledo: Mando de Doctrina, Ejército de Tierra español 2012.

[7] Gratch J, Marsella S. Fight the Way you Train: The Role and Limits of Emotions in Training for Combat. Brown J World Aff 2003: 63-72.
[8] Hübner S. Tiros de combate y defensa personal. Ripollet: ADS 1984 .

[9] LaFond J. The Logic of Steel, A Fighter's View of Blade and Shank Encounters. Boulder, Illinois: Paladin Press 2001.

[10] Haynes J, Rees G. Decoding mental states from brain activity in humans. Nat Rev Neurosci 2006; 7: 523-34.

[11] Thabot D. Judo óptimo, análisis y metodología. Barcelona: Inde 1999.

[12] Thiess G, Tschiene P, Nickel H. Teoría y metodolgía de la competición deportiva. Barcelona: Paidotribo 2004.

[13] Oliva A, Torres F, Navarro J. Combate Supremo. Tarragona: Club Karate Musoken 2002.

[14] Alba C. Jiu-Jitsu, la herencia de los Samurais. Madrid: Esteban Sanz 1994.

[15] Robles J. Defensa Personal. Toledo: Escuela Central de Educación Física 2007.

[16] Robles J, Alba C, Lumbreras V. Publicación doctrinal de instrucción de combate cuerpo a cuerpo e intervención no letal PD1-301. Toledo: Mando de Doctrina, Ejército de Tierra español 2010.

[17] Clemente VJ, Robles JJ. Respuesta Psico-fisiológica en diferentes situaciones de combate. Saarbrucken, Alemania: Academica Española 2012.

[18] Clemente VJ, Robles JJ. Respuesta orgánica en una simulación de combate. Sanidad Militar 2012; 68(2): 97-100.

(C) Aguirre-Puig et al.; Licensee Bentham Open.

This is an open access article licensed under the terms of the Creative Commons Attribution Non-Commercial License (http://creativecommons.org/licenses/ by-nc/3.0/) which permits unrestricted, non-commercial use, distribution and reproduction in any medium, provided the work is properly cited. 